\title{
Ficción y autobiografía en la construcción del sujeto lírico. Dos visiones contemporáneas del intimismo
}

\author{
Fiction and Autobiography in the Construction \\ of the Lyrical Subject. Two Contemporary Views \\ on Intimism
}

\author{
Joaquín Moreno Pedrosa \\ Universidad de Sevilla \\ jmoreno3@us.es \\ ORCID iD: http://orcid.org/0000-0001-9393-6243
}

\section{RESUMEN}

Dentro de la llamada generación de 1970 suele destacarse la visión del intimismo de los poetas novísimos y los afines a ellos, que tratan de evitar lo máximo posible en el poema las referencias a su intimidad y a las circunstancias de su realidad cotidiana. Para ello, hacen uso del repertorio de motivos culturales que se conoce como culturalismo, en una poesía concebida como independiente de la propia vida. Sin embargo, otros autores, coetáneos de los primeros, prefieren dejar que sus circunstancias vitales determinen la evolución de su obra artística. Para estos autores (entre los que puede citarse a Antonio Carvajal, Miguel d'Ors y Eloy Sánchez Rosillo), la poesía se construye con elementos de la propia vida y de la realidad circundante, aunque el resultado final sea una ficción. Y, de forma paradójica, el proceso de ficcionalización les permite descubrir lo que de esencial o universal hay en esas experiencias.

Palabras Clave: novísimos; generación del 70; Antonio Carvajal; Miguel d’Ors; Eloy Sánchez Rosillo.

\section{ABSTRACT}

In the Generation of 1970 it is usually emphasized the view on intimism of novisimos poets and others related to them, who try to avoid the references to their privacy and their real life circumstances in their poems. In order to achieve this, they use a repertoire of cultural motifs, known as culturalism, in a poetry considered independent from their own life. Nevertheless, other contemporary authors prefer that their vital circumstances prompt the development of their works. Some of these authors are Antonio Carvajal, Miguel d'Ors and Eloy Sánchez Rosillo and for them, poetry is erected from elements of their own life and the surrounding reality, even though 
the final result is fiction. Paradoxically, the process of fictionalization allows them to discover the essential and universal of these experiences. Rosillo.

Key words: Novísimos; Generation of 1970; Antonio Carvajal; Miguel d’Ors; Eloy Sánchez

Para el estudio de la poesía española del último cuarto del siglo XX, la crítica literaria viene usando de modo habitual el término generación — normalmente, en su acepción cronológica - como instrumento de separación y clasificación. Si bien es verdad que se trata de un concepto muy cuestionable (ver Mateo Gambarte, 2012), también es cierto que su uso suele estar desprovisto de cualquier interpretación histórica subyacente, y que se emplea únicamente como delimitación para exponer y analizar movimientos, grupos y autores diferentes pero coetáneos entre sí. En cualquier caso, uno de los más estudiados entre estos repertorios es el de los poetas nacidos entre 1939 y 1953 , tradicionalmente colocado bajo el marbete de generación del 70. Los más famosos de estos autores se dieron a conocer en la antología de José María Castellet Nueve novísimos poetas españoles, de 1970. A día de hoy, tanto el grupo de los novísimos como otros escritores que no fueron incluidos en la antología de Castellet, pero que se sumaron muy rápidamente a su estética, constituyen para la crítica el objeto de atención preferente en este período.

Entre los rasgos más representativos de estos poetas novísimos y los afines a ellos debe destacarse el tratamiento del sujeto lírico. Uno de los antologizados por Castellet, Guillermo Carnero, reconocía explícitamente como característica de su poesía y la de sus compañeros «la renuncia a la expresión directa del yo sentimental y confesional». Para llevar a cabo una «expresión indirecta del yo lírico», tanto él como sus compañeros recurrieron a motivos tomados del mundo de la cultura, en el procedimiento que se ha llamado culturalismo (1983: 54-55). Desde el principio, la crítica literaria señaló esta práctica como uno de los rasgos esenciales de los nuevos poetas. Julia Barella, por ejemplo, destacaba en la poesía de los novísimos «la ausencia de intimismo y la carencia de experiencias y sentimientos personales» (1988: 10). Barella también trató de hallar una explicación para esta «despersonalización» y ausencia del yo, concluyendo que «aceptar la limitación de un sujeto significa incluirse en la dualidad nacimiento muerte», y que los poetas novísimos evitaban toda referencia a la realidad por la concepción profundamente nihilista que tenían de ella (1981: 4). Esta visión nihilista conduciría a una crisis del concepto mismo de identidad, lo que haría tambalearse también la conciencia de la autoría. Finalmente, según la escritora leonesa, estos poetas acabarían constatando «la imposibilidad de definir las cosas por la desconfianza en el "yo" propio que las mira» (1983: 72). Estas apreciaciones se han mantenido hasta hoy en la crítica sobre la poesía novísima; en fechas recientes, Juan José Lanz subrayaba que los antologi- 
zados por Castellet y sus afines no buscaban tanto distanciarse del yo como excluirlo lo más posible de su obra, concebida como una estructura que se construye únicamente a partir de referencias culturales, «negando la realidad circundante al no incorporarla al poema» (1994: 4).

Al poco de publicarse la antología de Castellet, la mayoría de los novísimos y sus seguidores ya se declaraban inmersos en una evolución que, en muy poco tiempo, los haría distanciarse de estas prácticas iniciales. Guillermo Carnero, por ejemplo, aludía concretamente a «la pérdida del miedo a la expresión directa» y a la desaparición de «la censura del autobiografismo lírico», de la que consideraba ejemplos a Antonio Colinas, Luis Antonio de Villena o él mismo (1983: 54-56). Como había ocurrido con anterioridad, la crítica se hizo eco inmediatamente de los nuevos planteamientos novísimos: José Olivio Jiménez, por ejemplo, apreció una evolución desde el «radical distanciamiento entre experiencia y poesía, entre vida personal y lenguaje poético» de estos poetas, hasta los últimos libros de Colinas, Villena, Félix de Azúa, Antonio Martínez Sarrión y Jenaro Talens, así como en el renovado interés por la obra de Juan Luis Panero, caracterizada por una mayor presencia del elemento vital en su poesía, hasta hacerse todos ellos más próximos y parecidos a los poetas del cincuenta que a los miembros de su propia generación (1985: 47). En fechas más recientes, Juan José Lanz también ha visto en la poesía de aquellos años un empleo distinto del culturalismo, que ya no serviría para excluir el yo lírico del poema, sino para construir uno a partir de la asunción de determinados modelos de la tradición. El regreso a la tradición, por tanto, se integraría en la nueva tendencia «de recuperación progresiva del yo lírico y de expresión de su experiencia en el poema», en lo que se ve como un "giro hacia la realidad, hacia lo formulable lingüísticamente», una vez que se omite el paso intermedio, el «personaje histórico inserto en la tradición cultural» del monólogo dramático histórico:

Por lo tanto, al convertirse la tradición en una vía de conocimiento del yo, esa misma tradición quedará transformada por las proyecciones de la propia personalidad, que viéndola desde una perspectiva contemporánea, tratará de buscar en ella aquello que es permanente en el hombre. La tradición, así, quedará integrada dentro del fluir vital y de la memoria, en una confluencia amalgamada de vida y cultura (1994: 5).

Como ejemplo de esta nueva actitud, Lanz destaca Los trucos de la muerte (1975) de Juan Luis Panero, Sepulcro en Tarquinia (1975) de Antonio Colinas, Ciego en Granada (1975) de Miguel d'Ors, El viaje a Bizancio (1976) e Hymnica (1979) de Luis Antonio de Villena, Pasar y siete canciones (1977) y Farra (1983), de Félix de Azúa, Scholia (1978) de Luis Alberto de Cuenca, Tabula rasa (1985) de Jenaro Talens, Siesta en el mirador (1979) de Antonio Carvajal, u Horizonte desde la rada (1983) y Acedía (1986), de Antonio Martínez Sarrión. 
En líneas generales, casi todos los críticos suelen exponer en términos muy similares a estos la visión del intimismo que se da en la generación del 70. Por ejemplo, Ángel Luis Prieto de Paula sintetiza y enumera los rasgos generales que caracterizan a estos poetas en su monografía Musa del 68. Claves de una generación poética. Sin embargo, el crítico salmantino precisa que dichos rasgos proceden de «los compases iniciales» de la generación, alrededor de 1970 , y que por tanto solo son definitorios de un grupo de autores dentro de ella, excluyendo a quienes no participaron de esa misma estética, bien por diferencias artísticas, bien por haber editado sus libros o haber recibido el reconocimiento público más tardíamente (1996: 103-104). El primero de esos rasgos, y el más directamente relacionado con lo que aquí se trata, es la «reserva sentimental», que Prieto de Paula define como «la falta de asentimiento necesario del poeta con el yo del que parece emanar el poema (aun cuando, como sucede muchas veces, se produce entre ambos la simulación de su coincidencia)» (1996: 105). En unas ocasiones, esta desconexión entre poeta y poema se manifiesta en la subordinación de la poesía a otras disciplinas artísticas y, sobre todo, a la vida. En otras, tiene lugar en forma de restricción sobre la expresión de los sentimientos:

No tiene por qué ocultarse siempre la sustancia emotiva del poema, pero hay formas de conseguir que esta no se precipite descontroladamente hacia la sentimentalidad, bien mediante la inserción de elementos antipoéticos en el tema, el tono o el lenguaje, bien mediante determinados quiebros humorísticos. Un modo peculiar de refrenar la sentimentalidad tiene lugar cuando el curso lírico se ve interrumpido por consideraciones diríase que «profesionales» con las que un poeta incluye en su composición precisiones sobre oficio, la técnica o el contexto extraliterario del acto de la escritura (1996: 106-107).

Hasta aquí, la «reserva sentimental» descrita por Prieto de Paula bien puede aplicarse sin restricciones a toda la generación del 70. Sin embargo, la causa que el crítico salmantino le atribuye solo podría ser aceptada por los autores novísimos y los afines a su estética: nos referimos a «la indefinición con que el poeta considera la función de la literatura, y de la suya en concreto». Según Prieto de Paula, esta indefinición se basaría en «el escepticismo sobre cualquier modo de fe totalizadora, y por ende codificable en una formulación dogmática», abandonadas tanto la estética socialrealista como «también la romántica (consideración del yo personal como materia directamente convertible en nutriente del poema)» (1996: 110-111). En efecto, los ejemplos aducidos de esta actitud (Carnero, Vázquez Montalbán, José María Álvarez, Félix de Azúa, y Ana María Moix) pertenecen todos ellos a la antología de Castellet, y el mismo Prieto de Paula reconoce que «hacia la mitad de la década del setenta, la falta de asentimiento necesario deja de ser un requisito tan riguroso, y la nota distanciadora que predominara en los comienzos fue atenuándose» (1996: 117). 
Incluso hoy día, con una mayor distancia y perspectiva, este planteamiento apenas se ha visto modificado. Por ejemplo, en la exhaustiva monografía de Ramón Pérez Parejo, Metapoesía y crítica del lenguaje. De la generación de los 50 a los novísimos, se atribuye de modo general a todos los miembros de la generación del 70 la misma visión del poema que tenían los antologizados por Castellet, «como tejido de citas y referencias a innumerables centros de la cultura». Desde este punto de vista, «el Autor es solo una localización donde el lenguaje (ecos, repeticiones, intertextualidades) se cruza continuamente» (2002: 476). Los novísimos, siempre adelantados a los demás miembros de su generación, serían los protagonistas de la renovación poética que se llevó a cabo respecto a toda la literatura anterior:

A mi juicio, una de las principales claves del distanciamiento estético entre los novísimos y las generaciones anteriores es la diferente concepción del yo poético. Los novísimos huyeron de una convención intimista de carácter confesional; huyeron de la plasmación explícita del yo autobiográfico. En lugar de exponer su subjetividad en medio de un imaginario real, es decir, en medio de la referencia del mundo objetivo que les rodea, muestran su yo en un imaginario cultural (2002: 252-253).

El fundamento de esa «diferente concepción del yo poético» sería, a su vez, la visión del lenguaje que tienen estos poetas. Según Pérez Parejo, lo característico de esta generación es que «confiesa explícitamente la insuficiencia del lenguaje y su incapacidad para expresar la realidad y el pensamiento», lo cual le lleva a una «crítica metaliteraria integral del poema» y a un «discurso paralelo al de la elocución lírica», que terminarán «por neutralizar el discurso lírico mediante la reflexión sobre su imposibilidad» (2002: 266-267). También Juan José Lanz, en uno de sus últimos trabajos sobre esta generación, ha centrado su estudio exclusivamente en los poetas novísimos y «nuevos» (autores afines a los primeros, pero no incluidos en la antología de Castellet). Según Lanz, lo que caracterizaría «más eficazmente» a todos los autores de la generación del 70 (que él llama «del 68») es «la concepción del lenguaje como único elemento capaz de llevar a cabo una ordenación de la realidad en el texto poético, capaz de construir una realidad autónoma en el poema» (2011: 35). Sin embargo, lo cierto es que esa visión del lenguaje que provoca la «imposibilidad» del texto lírico, según Pérez Parejo, o su «autonomía», como quiere Lanz, no es compartida por todos los compañeros de generación de los novísimos y sus seguidores. Hay, de hecho, varios miembros de la generación del 70 que han mantenido a lo largo de toda su trayectoria una visión constante de la poesía como actividad esencialmente vinculada a la realidad, a la propia vida y a la de los demás. Estos autores, además, no comparten el afán de los novísimos por presentarse como el punto culmen de un proceso de ruptura o innovación; antes bien, su visión poética entroncaría plenamente con la de la generación del 27 , los autores de la posguerra y la generación del 50, y 
se prolongaría de modo mayoritario hasta el panorama de nuestros días. Como ha expuesto José Luna Borge en su libro La generación poética del 70, se trata de unos poetas que, a partir de 1975, empiezan a publicar «una obra que nada tenía que ver con el aire de Escuela novísima y que ha ido creciendo en calidad y en cantidad convirtiendo a sus autores en los verdaderos protagonistas de la generación» (1991: 133). Según este punto de vista, lo que Luna Borge considera que hicieron los poetas novísimos, tras el abandono de su estética inicial, fue «seguir los nuevos planteamientos poéticos que iban surgiendo bajo el impulso de los nuevos (hubo abandonos y cambios de registro de auténtico infarto)» (1991: 230). Otros críticos tienen una visión muy similar a esta. Para Pedro Provencio, por ejemplo, lo que se produce en el contexto poético español a mediados de los setenta, más que una evolución en los poetas novísimos, es un relevo: estos, «agotados, desinteresados por su clasificación generacional o simplemente reconvertidos, pero sin perder notoriedad», dieron paso a otros miembros de su misma generación, cuya obra marcaría los pasos seguidos por las generaciones sucesivas (1993a: 88). Son los autores que algunos críticos habían señalado como «independientes» o «francotiradores»: Antonio Carvajal, Mario Hernández, Juan Luis Panero, Miguel d'Ors, Lázaro Santana, Agustín Delgado, Eloy Sánchez Rosillo, etc. (Barella, 1988: 10; Provencio, 1993b: 24; Lanz, 1994: 4).

De manera muy confusa, la obra de estos autores, así como otros más jóvenes, se engloba a veces bajo el término «poesía de la experiencia». Como se sabe, tal denominación procede de la obra de Robert Langbaum The poetry of experience. The dramatic monologue in modern literary tradition. En ella, Langbaum define toda la literatura occidental posterior a la Ilustración como inscrita en una tradición, denominada por él como «poesía de la experiencia», que trata de superar la separación establecida por el empirismo entre los hechos y su valoración, partiendo de «aquello que percibimos en los instantes de experiencia inmediata, sin ayuda del análisis» (1996: 78). Este tipo de poesía, que Langbaum rastrea hasta las Lyrical Ballads (1798) de Wordsworth, se caracteriza por presentar fusionados el objeto percibido, el pensamiento y los sentimientos que en la poesía anterior estaban solo yuxtapuestos, de modo que la validez de sus ideas no está en función de un sistema público de valores sino de «la experiencia genuina de una persona concreta» (1996: 111). Esta persona no tiene que coincidir necesariamente con el autor del poema, sino que es un observador que «busca fuera de sí la experiencia de su poema» para «desarrollar un alma o identidad» (1996: 116), la cual se identificaría con el poema mismo; por tanto, según Langbaum, habría que considerarlo más bien «un personaje en una acción dramática, un personaje al que el poeta asigna las cualidades necesarias para que el poema le ocurra» (1996: 119). El ejemplo más claro de esta perspectiva se localiza en los monólogos dramáticos publicados por Browning y Tennyson en 1842; en ellos, la atribución de la voz poética a personajes moralmente reprobables obedece al deseo de crear una 
tensión entre la perspectiva directa del personaje y las ideas morales adoptadas socialmente por el lector (1996: 155). En los monólogos dramáticos que componen The ring and the book, de Browning, descubre Langbaum una superación de la dicotomía entre el poeta mimético y el demiúrgico: por un lado, el poeta se limitaría a manipular los hechos existentes; pero, por otro, el significado global del poema no existiría como tal antes de que este fuera escrito, así que no podría ser imitado. Por tanto, la poesía de la experiencia es «una literatura que se vuelve sobre sí misma, generando sus valores propios» (1996: 362).

La poesía española no ha permanecido ajena a esta tradición descrita por Langbaum. En el homenaje que la revista La caña gris dedicó a Cernuda en 1962, José Ángel Valente incluía al poeta sevillano dentro de lo que se ha llamado poesía meditativa, con su más próximo antecedente en don Miguel de Unamuno. Como rasgo más característico de esta orientación lírica, Valente destacaba la «combinación del análisis mental con la volición afectiva» (1962: 34), y consideraba que la «culminación del proceso poético y elemento definitorio del mismo» era la «unificación de la experiencia» (1962: 36). Otros participantes en el mismo homenaje coincidieron en atribuirle el mismo rasgo a la poesía de Cernuda, señalando además que su principal consecuencia era la reconstrucción por parte del lector de la experiencia descrita, y su asunción como propia. Así lo expuso Jacobo Muñoz:

\begin{abstract}
Al poeta le ha sido posible introducir, en rara síntesis, pasión, inteligencia e imaginación en su obra, pero sin hablar nunca expresamente de emoción (y mucho menos de sentimiento, que tiene poco o nada que ver con la poesía). Y, sin embargo, la emoción ha sido expresada. El lector la ha recreado dentro de sí, completando de esta manera la tarea del poeta (1962: 163).
\end{abstract}

Según Muñoz, el poeta alcanzaría este logro, principalmente, a través del rigor compositivo, y de distintos procedimientos objetivadores (1962: 164). Se trata, como puede verse, del mismo distanciamiento y la misma fusión de objeto, pensamiento y sentimientos que se describen en The poetry of experience. Sin embargo, la caracterización que muchos críticos han trazado de la poesía del 70 como «poesía de la experiencia» no tiene en cuenta los postulados de Langbaum; lo más común es confundir esta opción estética con una poesía descriptiva de contenido autobiográfico. Es el caso de José Olivio Jiménez cuando dice que, por la «relación literal entre experiencia y palabra poética», «los poetas del 50 fueron y son, todos, poetas de la experiencia» (1985: 45). Tampoco es raro que algunos críticos, a pesar de ser conscientes del proceso de construcción de una identidad lírica que implica este tipo de poesía, como Elena Barroso, la definan, de una forma que puede llevar a confusión, como una «reflexión generalizadora de la anécdota personal y biográfica del poeta» (1991: 18). Sin embargo, Barroso ha señalado bien el diseño de un yo lírico, diferente del poeta, como la diferencia fundamental entre el «neorromanticis- 
mo» que, según ella, aparece en la poesía de la generación del 70, y el romanticismo clásico (1991: 46). Por otra parte, en algunos trabajos se admite la confusión e inexactitud que comporta este uso del término poesía de la experiencia, aunque dicho uso se mantenga. Es el caso de la antología de Araceli Iravedra titulada, precisamente, Poesía de la experiencia. En su estudio introductorio, Iravedra advierte de que la adopción de este nombre para referirse a la principal corriente lírica española desde los años ochenta constituye un «desplazamiento conceptual», y que se ha difundido a pesar de «que los postulados de Langbaum no constituyan un referente directo para estos poetas» (1997: 34-35). De esta manera, «la laxitud con que viene siendo utilizado ha acabado por convertirlo en un cajón de sastre en el que se amontonan tal vez demasiadas cosas» (1997: 26), «reproduciendo la imprecisión que ello supone» (1997: 31). La propia autora ofrece varios ejemplos en que la descripción que se hace de la poesía de esos años utiliza experiencia y poesía de la experiencia de forma indiscriminada, y sin tener en cuenta las ideas de Langbaum, como es el caso de Benjamín Prado, Enrique Molina Campos, Luis Antonio de Villena y Miguel García Posada (1997: 14-20). Sin embargo, Iravedra prefiere mantener esta denominación, a pesar de sus ambigüedades, por dos motivos. En primer lugar, porque considera que el uso la ha impuesto definitivamente sobre las demás (1997: 25). En segundo, porque la poesía española de este período se caracteriza por unos rasgos de estilo («narratividad, ironía, lenguaje coloquial...») y un relativismo posmoderno que, según la autora, no desentonan del todo con la perspectiva del sujeto lírico y con la crisis de valores posterior a la Ilustración que se describen en The poetry of experience. Por ello, no habría que considerarla «después de todo tan ajena a aquel exponente de la tradición lírica moderna definida por Langbaum» (1997: 32-33).

En otros trabajos, sin embargo, sí se aprecia mejor una aplicación precisa de los criterios de The poetry of experience. Así, María Victoria Utrera observa que los postulados de Langbaum solo son heredados por lo que actualmente se denomina poesía de la experiencia cuando «se entiende esta como experiencia de un sujeto real desdoblado y se separan el yo poético y el real» (2005: 144). Algunos críticos, por su parte, han preferido emplear denominaciones menos confusas. Así, el retorno a la anécdota personal ha llevado a Juan José Lanz a hablar de «nuevo romanticismo» para referirse a esa "poesía de la experiencia» española. Sin embargo, Lanz precisa que suele haber en ella un distanciamiento del yo mediante cierta ficción autobiográfica, para evitar el patetismo, y que habitualmente elige un tono narrativo, con un desarrollo lógico de principio a fin. Según Lanz, hay en muchos de estos poemas consciencia de la ficcionalización de la vida que supone la literatura, de la diferencia entre poesía y realidad (1991: 38-39). En cualquier caso, está claro que el nombre de poesía de la experiencia, que Robert Langbaum utilizó para designar una perspectiva del sujeto en la lírica occidental a partir del siglo XVIII, no es adecuado para designar una manifestación poética española en auge desde fi- 
nales de los setenta. Es por eso que, buscando un término menos equívoco, José Luis García Martín prefirió hablar de poesía figurativa para referirse a la vertiente más intimista de la poesía del 70, frente a la poesía surrealista o la minimalista (1992: 208-227).

En este trabajo se ha procurado evitar, por un lado, la extrapolación de los planteamientos novísimos a toda la generación del 70; por otro, que las distintas visiones del intimismo que se dan entre ellos se confundan con la ambigua etiqueta de poesía de la experiencia. Por esta razón, a continuación se exponen las ideas más significativas que sobre la construcción del sujeto lírico pueden encontrarse como alternativas a la solución novísima. Para ello, se ha escogido a tres autores de la generación del 70 que se han mantenido fieles a una trayectoria personal e independiente desde el comienzo de su actividad poética, al margen de la estética castelletiana y sus sucesivas revisiones. La selección de estos tres autores viene dada por la heterogeneidad de sus respectivos planteamientos filosóficos, éticos y estéticos, en ocasiones radicalmente opuestos, que sin embargo no les ha impedido llegar a conclusiones muy similares en sus poéticas. Estos autores son Antonio Carvajal, Miguel d'Ors y Eloy Sánchez Rosillo.

En los tres autores seleccionados hay un rasgo común que enseguida resulta llamativo: su resistencia, casi hostil, a elaborar una poética. En la obra de todos ellos abundan los momentos metapoéticos, y podemos encontrar incluso poemas enteros colocados bajo el título explícito de «Poética». Pero estos textos suelen desarrollar una argumentación paradójica, como la dedicatoria de Serenata y navaja, de Antonio Carvajal (1983: 69), y los versos de «Un mágico alfabeto», de Miguel d'Ors (2001: 203). O, también frecuentemente, ocurre que uno de esos poemas expone una visión distinta u opuesta respecto a otros del mismo tema, como en los ejemplos de Eloy Sánchez Rosillo «Camino del silencio» (1995: 61) y «Límites» (2008: 48). Es indudable que, de esta manera, dichos textos ejemplifican fielmente la naturaleza misteriosa, compleja y, con frecuencia, contradictoria de la creación literaria. Pero, a la hora de sistematizar su pensamiento poético, y plantearlo de modo lógico y derivado, todos estos autores han expresado su reticencia sin disimulo. El más veterano de ellos, el granadino Antonio Carvajal, colocaba estas palabras al frente de sus poemas en la antología Nueva poesía española, de Enrique Martín Pardo, publicada en 1970:

He renunciado de antemano a participar en la frivolidad ambiental, convencido de que únicamente los hechos nos dan a conocer. Y, decidido a ser tan libre cuanto me sea posible, trabajo para que sean mis obras, y no las palabras, quienes me definan. [...] Ocupado en estudiar la Poesía con todo entusiasmo y en la medida de mis posibilidades, todavía no he tenido tiempo de garabatear una poética a mi medida. Actúo, así, con plena libertad, autenticidad personal, de la que el poema ha de ser un reflejo. Esta es la única conclusión a que he llegado hasta hoy (Martín Pardo, 1990: 16-17). 
Treinta y cuatro años más tarde, en la redacción de unos «Propósitos poéticos» para la fundación Juan March, el autor granadino volverá a insistir, siguiendo a Unamuno, en que las poéticas no han de ser preceptivas sino «posceptivas», y que toda reflexión sobre su propia creación no procede de un juicio previo, sino «del frágil análisis de lo ya realizado» (Carvajal, 2004b: 15-16). Por su parte, Miguel d'Ors, que empezó a publicar su poesía en 1972, terminaba la primera antología de su obra manifestando que la sujeción a una poética determinada le parecía una «operación melancólica», consistente en «rechazar quién sabe cuántas otras posibles poéticas no menos aptas para llevarnos a la Belleza o al fracaso», y que consideraba más relevantes las cuestiones de artesanía que las de Poética (1992: 206). Siete años más tarde, repetirá estas mismas opiniones en la nota final a su libro Hacia otra luz más pura (1999: 93). Finalmente, cuando, en el año 2008, publique una colección de fragmentos y anotaciones sobre la creación poética y otros temas dispersos, d'Ors atribuirá su renuencia a profesar una poética a la creencia de que la buena poesía procede del talento de su autor, y no de su pensamiento poético. Además, puesto que la poesía es creación, el autor gallego considera que toda poética está condenada a quedar superada, tarde o temprano, por un nuevo logro que transgreda e invalide sus principios (2008: 187-188). Por último, el más tardío de estos autores en publicar su primer libro, Eloy Sánchez Rosillo, aprecia — de forma similar a Carvajal - una oposición entre la autenticidad artística y el seguimiento de una poética: «Como cualquier poeta que aspire a ser auténtico, no he escrito nunca ateniéndome consciente y deliberadamente a ninguna poética propia ni a las recetas de ninguna tendencia, escuela o grupo» (2005: 17-18). También, de manera análoga a d'Ors, el autor murciano considera que la poesía tiene un componente esencial de innovación y sorpresa, y por tanto está destinada a desbordar cualquier intento de previsión o planificación: «Mis poemas, mis libros, son el resultado de una aventura personal no prevista ni programada (de lo contrario no sería tal aventura), una aventura que he vivido siempre con perplejidad» (2005: 18).

No sabemos si, en el momento de expresar tales reservas, estos tres autores opinaban, como nosotros ahora, que la inflación de preceptos estéticos y la ambición teórica habían contribuido en no poca medida a la devaluación y caducidad de la moda novísima. Sin embargo, de sus palabras sí podemos deducir que todos ellos basan su concepción de la poesía en lo que Carvajal y Sánchez Rosillo denominaban «autenticidad», es decir, la interrelación explícita entre su obra y su vida, constituyendo con frecuencia las circunstancias de esta última la materia prima del poema. La consecuencia principal de esta concepción es que no hay en la teoría literaria de ninguno de estos tres poetas cuestionamiento o anulación del yo. Antonio Carvajal, por ejemplo, siempre ha reivindicado «la inocencia en la poesía, digo la inocencia de presencia del yo» (2004a: 11). De acuerdo con su voluntad de no ocultar la relación entre su vida y su poesía, la variación de sus circunstancias vitales y su visión de la realidad 
ha provocado una variedad de tonos y recursos expresivos que caracteriza la evolución de su obra. El poeta granadino es muy consciente de esta repercusión, que aprecia hasta en sus más concretas manifestaciones métricas:

Mi segundo libro no debía ser una continuación, ni en los temas ni en las formas, de Tigres en el jardín. No podía serlo: Muchos sustentos básicos de mi vida se habían roto o estaban resquebrajados, y aquel esplendor inicial de mi obra primera se reducía progresivamente a sombras, aunque yo persiguiera, denodadamente, apresar sus últimos fulgores. Cualquier lector de mi poesía puede apreciar, con una simple mirada, la evidente quiebra de las formas, manifestación sensible de una subversión más honda: El acompasado fluir de los alejandrinos, los equilibrados endecasílabos, casi siempre unos y otros agrupados en sonetos, se ven sustituidos en Serenata y navaja por una versificación generalmente abrupta, en que la melodía del verso y el fluir de los conceptos entran en colisión. La lira, la silva, otras estrofas polimétricas, delatan una nueva visión, alterada, deformada, del mundo (Carvajal, 1994: 7).

Con igual claridad expresaba Miguel d'Ors su identificación con el sujeto lírico de sus poemas, tanto en su primer libro, donde dejaba «escrito lo que soy y lo que he sido» (1972: 74), como en la antología Punto y aparte, en la que seguía minuciosamente el rastro de algunas referencias culturales de sus poemas hasta su propia experiencia, concluyendo: «El culturalismo es, por tanto, autobiográfico» (1992: 212). Desde el principio, también la crítica ha sido consciente de este rasgo de la poética de d'Ors; comentando su primer libro, José Luna Borge destacaba su orientación hacia «la veta romántica, intimista y amorosa» (1991: 219). Esta visión del autor gallego se mantendrá constante hasta la nota inicial de uno de sus últimos libros publicados:

Digo «el poeta», y no «el personaje poético», como ahora parece obligado por la moda. Ya se sabe: una creación, una ficción, una máscara... ¡Un cuerno! Como si esa máscara, caso de que se la quiera uno fabricar, no tuviera que ser inevitablemente fabricada con pedazos arrancados del propio rostro. ¿Dónde, si no en la vida vivida, podrían encontrarse los materiales para esa construcción? A fin de cuentas, si o poeta é um fingidor, no es menos cierto que finge que es dolor... el dolor que de veras siente. Por eso digo siempre «el poeta»: yo (2005: 7).

Desde este punto de vista, la identidad del poeta será también el origen de la unidad que subyace a su obra. A dicha causa le atribuye d'Ors, en sus «Dos palabras del autor», la coherencia que tienen entre sí los muy variados poemas de su libro Sociedad limitada: «en cualquier caso parece claro que, haga uno lo que haga, como inevitablemente está en cada una de las cosas que hace, todas ellas habrán de tener necesariamente en la base la unidad de uno» (2010: 8). Por lo que respecta a Eloy Sánchez Rosillo, el poeta murciano parte del bienhumorado reconocimiento de que «con mucha frecuencia mis poemas tienen su origen en hechos de mi propia vida - que son los que me caen más a mano-》 (2005: 31). Esto le lleva a concluir, no sin cierta reserva, que «para bien o para mal, y sin ninguna duda, el personaje que yo haya podido crear en 
mis obras es alguien que se parece bastante a mí mismo» (2005: 32). Desde una perspectiva similar a la de Antonio Carvajal, en la visión poética de Sánchez Rosillo este vínculo entre el yo real y el literario tiene su consecuencia en el plano textual, de manera que a cada momento y situación en la vida del autor le correspondería un tono, una dicción determinada para los poemas escritos en tales circunstancias. Esta identidad entre la expresión y lo expresado, entre la forma poética y el fondo, de contenido biográfico, es el tema del poema «Este abril», donde se contraponen su yo juvenil y su yo maduro, con sus respectivas expresiones literarias. En el caso del primero, dice que había

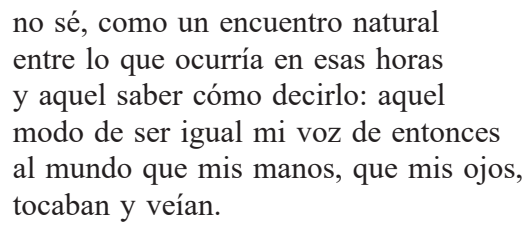

La misma coherencia se da, en su madurez, entre la experiencia adquirida a través del desengaño y la desilusión, y su correspondiente tono lírico. Sin embargo, precisamente por el carácter negativo de esa experiencia, en el presente tiene miedo de encontrarse consigo mismo, «de decir / mi verdad del presente con la voz / oscura que ahora tengo» (Sánchez Rosillo, 1995: 200). Ángel Luis Prieto de Paula ha subrayado esta correspondencia entre poesía y vida que se da en la poética del autor murciano, afirmando que «para Rosillo la poesía es necesariamente historia de una vida». También ha visto sus consecuencias textuales, al señalar que cada uno de los libros del autor murciano «es un espacio armónico cuyo clima proviene del encuentro de las composiciones nacidas en un determinado segmento cronológico, impregnadas por tanto del mismo espíritu vital» (Prieto de Paula, 1991: 266). La «autenticidad» de la que hablan los tres poetas citados, esa natural derivación entre la vida del autor y su obra, es un hecho relevante dentro de la generación a la que pertenecen, porque sustenta su concepción moral de la poesía, y por tanto la función trascendente que le atribuyen.

No hay que confundir esta autenticidad con una ingenua identificación romántica de la vida y la obra, de los sentimientos y experiencias del autor con el contenido del poema. Ambos extremos aparecen claramente diferenciados en la teoría poética de Antonio Carvajal. En su libro de conversaciones con la profesora Joëlle Guatelli-Tedeschi, reconoce la necesidad de mantenerse distanciado de sus propias emociones y experiencias mientras está componiendo el poema, «porque en el momento de escribir lo que estoy haciendo es una obra de arte, no levantando un acta notarial de otro tipo de experiencia». Este distanciamiento haría referencia únicamente a su propio estado psicológico, no a las referencias autobiográficas o al contenido anímico del poema, que constituyen su materia básica: «En el acto de escritura es la emoción del poema la 
que tengo, y la emoción de lo evocado está en él, pero sin su apremiante presencia» (Guatelli-Tedeschi, 2004: 183). En cualquier caso, ninguno de estos elementos personales tiene de por sí naturaleza literaria, y solo cuando adquieren su configuración formal definitiva en el poema pasan a formar parte propiamente de $-\mathrm{O}$ a ser recreados en- la obra artística:

[...] los sentimientos, las ideas, las creencias, las experiencias, los sueños, las pasiones, los deseos, los desvelos, las tendencias hacia lo sublime, las plenitudes o las carencias íntimas, no son sino un magma informe que nada «dize» hasta que se ordenan mediante el arte en un poema que nos aboca a lo inefable (Carvajal, 2002: 18).

En esta distinción entre contenido psicológico y construcción formal, correspondería a la segunda el logro de la validez estética; de manera que, sea cual sea el contenido espiritual del poema, si su autor no logra una expresión artística convincente, aquél quedará sin efecto, independientemente de su valor moral o intelectual. Por esta razón, y citando a Aleixandre, Carvajal suele afirmar que «en Poesía, lo que no está bien dicho, no está dicho» (1995: 25-26). La composición de un poema, entonces, vendría a ser una tarea de selección: las referencias procedentes de la propia vida constituyen su materia básica, pero es necesario distanciarse y adquirir cierta perspectiva sobre la experiencia que les dio origen. Este proceso de selección es lo que ha llevado al poeta granadino a declarar que «suelo escribir no a partir de lo que vivo sino de lo que contemplo» (1995: 135). En la contemplación se escogen los elementos que se incluirán en el poema, mientras que otros son desechados, en una memoria voluntariamente selectiva que vendría a urdir la ficción poética. Se trata del proceso que Antonio Chicharro ha descrito en estos términos:

En efecto, la poesía para Carvajal es algo más que un artefacto ornamental, un modo de duplicidad verbal de una realidad exterior determinada. La poesía es por el contrario el resultado de una comprensión estética del mundo y de un diálogo con él, al tiempo que la invención de una realidad de naturaleza ideológico-estética, en la que se dan cita múltiples componentes, sometido dicho proceso creador por lo general a una condición pragmática de acción y comunicación auténticas (2000: 68).

Miguel d'Ors aprecia también la necesidad del distanciamiento y la selección de los materiales biográficos para su inclusión en el poema. Esta selección se llevaría a cabo, en primer lugar, sobre aquellas experiencias que ya han sido asumidas por el poeta y que este considera que forman una parte esencial de su propia identidad, aunque sea a costa de su exactitud histórica; pues, según afirma el poeta gallego, «los recuerdos solo son poéticos cuando se nos presentan suficientemente diluidos y deformados; en definitiva, suficientemente transmutados en alma» (1992: 216). En segundo lugar, se eliminarían todos los elementos y circunstancias que pudieran distorsionar la visión que el poeta 
tiene de esas experiencias asumidas del pasado, para ofrecerlas en toda la nitidez del significado que se les atribuye. Tal es el tema de su poema «Del olvido»:

\author{
Pero no es la Memoria \\ mi musa: es el Olvido. \\ Solo él hace Palabra \\ el tiempo ya vivido; \\ solo él, que fue borrando \\ en mí lugares, ruidos, \\ rostros, mentiras: todo \\ lo que no era yo mismo (1991: 40-41).
}

Por tanto, la autenticidad que practican estos tres autores es una actitud muy diferente de la fidelidad histórica o de la sinceridad. Se trata, ante todo, de una categoría textual, no psicológica o moral, y como tal debe ser considerada. Según dice d'Ors, «la sinceridad, o no tiene la menor importancia literaria o es una virtud del estilo». La congruencia entre la propia vida y la obra vendría a ser, ante todo, una decisión estética, y su plasmación en el poema sería cuestión de dominio de la técnica necesaria: «El texto crea la sinceridad, por decirlo así; y la crea cuando acierta a expresar las cosas. [...] A fin de cuentas, solo el buen poeta puede ser sincero» (2008: 29). Algunos críticos han sabido ver la legitimación artística que el dominio de la técnica le concede a la expresión de ideas y opiniones personales en la poesía de Miguel d'Ors. José Luna Borge, por ejemplo, al reseñar la mezcla de «poemas religiosos, satíricos, amorosos, canciones tradicionales, etc.» que presenta su obra, concluye que «el combinado, sin embargo, no disuena porque sobre esta poesía pesa una forma de hacer y un estilo personales y diferenciadores» (1999: 58).

Una variante de la «sinceridad» que menciona d'Ors sería el realismo de los poemas. La obra del autor gallego se caracteriza, entre otros recursos, por las enumeraciones caóticas de intención descriptiva, y por una minuciosa adjetivación que pretende dotar a cada elemento de esas enumeraciones del mayor verismo posible, haciéndolo aparecer ante el lector en toda su concreción y viveza. La sensación de realismo que obtiene d'Ors de estos recursos es, por tanto, un artificio retórico, y ello le ha llevado a exclamar humorísticamente: «¡Dios mío! ¡Cuánta imaginación se necesita para ser realista!» (2008: 31). El poeta gallego ha dedicado muchos poemas a reflexionar irónicamente sobre la apariencia de autobiografía que con tanta frecuencia tienen sus poemas. Si bien en ningún caso ha negado el origen que en su propia vida tienen los elementos y referencias de sus poemas, también se ha referido al proceso falsificador que el recuerdo lleva a cabo sobre el pasado. Este es el caso de «Palinodia», donde dice: «ya sé que todas tus historias son mentira,/ que nada sucedió como tú me lo pintas./ Déjame en paz, memoria; no me cuentes mi vida» (1994: 42). En otros casos, ha reconocido la urdimbre de imaginación y técnica con la que, en 
el poema, recrea el sentimiento de nostalgia por la infancia, sentimiento de nostalgia que se encuentra intensificado por la pericia artística y que, de ningún modo, se corresponde unívocamente con el que experimenta el propio poeta. Así lo plantea d'Ors en «Información sobre el tiempo»: «La infancia es sobre todo / trabajo de ficción. / Confieso, con la pluma / puesta en el corazón, / que mis versos la añoran / bastante más que yo» (1999: 55). Esta consciencia de la ficción poética ha llevado al autor gallego a constatar, en otro de sus textos metaliterarios, que en la obra no hay más que palabras impresas, y que ellas crean y sustentan cualquier contenido autobiográfico que el lector pudiera percibir, permaneciendo independientes para siempre de su creador. Nos referimos a «Posible arte poética»:

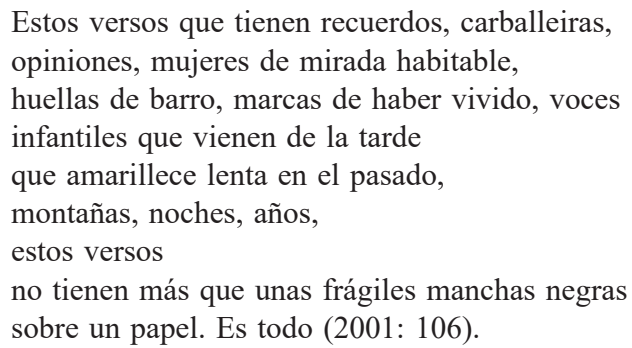

Naturalmente, este poema ofrece solo una parte del total que constituye la visión poética de Miguel d'Ors, una perspectiva parcial que debe añadirse y que complementa todo cuanto ya llevamos dicho sobre la identidad del autor real y el yo lírico, el autobiografismo y la autenticidad. Y, por último, el más joven de los autores aquí estudiados presenta también en su poesía una marcada tendencia hacia el tono intimista y autobiográfico, si bien es verdad que esta tendencia se halla habitualmente contrapesada por un amplio catálogo de procedimientos distanciadores. Entre los poemas de Eloy Sánchez Rosillo encontramos peripecias narradas en tercera persona, como «El mar estaba lejos» (1995: 23), incluyendo también sucesos explícitamente autobiográficos, como el descubrimiento de su vocación poética en «La muerte del silencio» (1995: 28). Pueden destacarse narraciones ecfrásticas como «El jinete», basada en el Reiterquartett de Haydn (1995: 31-34), o monólogos dramáticos como «Melville, en la aduana» (1995: 86-88), «De César Franck a Augusta Holmes» (1995: 94-96) y «Recanati, agosto de 1829» (1996: 25-27). Por último, hay un episodio narrativo en verso, con parlamentos de Heinrich von Kleist y su amada Henriette en forma de monólogos dramáticos, en una breve secuencia lírico-dramática titulada «Los pinares de Potsdam» (1995: 102-06). Pero, tal vez, el ejemplo de ironía y distanciamiento más bello y logrado que podamos encontrar en la poesía de Sánchez Rosillo sean los dos poemas titulados «Hortus rhetoricae». Como ejercicio técnico y argumentativo, dejan constancia de su concepción de la poesía como un oficio, así como del tratamiento irónico y 
objetivador que debe aplicarse a los propios sentimientos para que puedan convertirse en poema. Como expresión artística, los dos textos son una representación inmejorable del carácter paradójico o contradictorio, y simultáneamente verdadero, que tienen con frecuencia los sentimientos: cada fragmento es la exposición de una actitud opuesta a la del otro. El virtuosismo de este ejercicio perspectivista viene reforzado por la elección de la misma estrofa - la octava real - para ambos poemas, así como de siete de las nueve palabras portadoras de la rima:

La vida le ha entregado mucho menos de lo que él esperaba y soñó un día. Sus años juveniles, los más llenos de luz y de ventura, de alegría, pasaron. Y ahora ya le son ajenos los sueños e ilusiones que tenía. Piensa que en adelante será todo fuego apagado, muerte, de algún modo.

2

No, no le dio la vida mucho menos de lo que, adolescente, soñó un día. Su madurez, los años más serenos, ahora empieza a vivir. Y de alegría y frutos en sazón estarán llenos los sueños en agraz que antes tenía. La ilusión proveerá. De ningún modo puede aceptar que esté perdido todo (1995: 167).

Para el poeta murciano, el carácter de creación que tiene la poesía supone que esta no debe limitarse solo a reflejar la realidad o a representarla, sino que sus expresiones deben tener vida propia, un modo de ser específico distinto de su autor y del mundo, puesto que cada poema «crea vida a partir de la vida - como sucede en la naturaleza-, añade realidad a la realidad preexistente» (2005: 28). Para llevar a cabo esta creación, el autor dispone de «los innumerables y benditos útiles de la retórica» (2005: 29), cuya relación con los sentimientos y experiencias, según Sánchez Rosillo, está muy clara: «en el proceso de creación del poema es preciso que el material autobiográfico se universalice y se transforme en algo independiente de uno mismo» (2005: 31). Desde este punto de vista, la ironía y el distanciamiento ya no solo tendrían como objetivo la expresión artística eficaz, como quería Carvajal, o la depuración de todo lo accesorio y el hallazgo de lo esencial, según planteaba d'Ors, sino la transformación de la experiencia individual en un referente universal, que trascienda lo meramente autobiográfico. En la visión poética de los tres autores queda 
entonces planteada y resuelta una paradoja esencial del arte: si para los autores novísimos y similares el poema era «una estéril ficción», como dice José Luis García Martín, no menos cierto es que «la realidad solo a través de la ficción puede expresarse y conocerse. Tal es la paradoja del poeta y del hombre en general: no podemos conocer la realidad sin falsearla, sin modificarla» (1980: 52-53).

Cuando se destaca la interrelación que Carvajal, d'Ors y Sánchez Rosillo reconocen entre su poesía y su vida, no debe pensarse que la diferencia de sus planteamientos con las poéticas novísimas estriba en el intimismo o el autobiografismo. No tiene sentido seguir oponiendo el culturalismo, la ironía y el distanciamiento de los novísimos y otros poetas afines, con el intimismo, la emoción y el autobiografismo de los autores aquí estudiados. Partiendo de la base de que todos los elementos que aparecen en un poema son el resultado de una elaboración artística y son, por lo tanto, ficticios (ver García Martín, 1996: 26-29), parece lógico pensar que los materiales con los que se elabora dicho artificio procederán de una experiencia del autor, bien real y directa, bien mediatizada por el mundo de la cultura, y serán también, en consecuencia, autobiográficos. La diferencia está en la concepción del lenguaje utilizado en el poema, bien como una estructura autónoma, bien como un instrumento de representación y comunicación, por imperfecto que sea. Guillermo Carnero lo explica con gran precisión. Según él, su generación se opuso a la poética dominante en la España de su tiempo, que quedaría reducida a dos líneas fundamentales: «el realismo social y el intimismo primario». Lo fundamental de estas dos líneas sería «la poesía entendida como mensaje, tanto si este es de ámbito político y colectivo como individual y egocéntrico» (2004: 22). Con este tipo de poesía se refiere a la que transmite «significados no problemáticos en textos cuya lectura se vuelve automática, por su escasa desviación de la lengua estándar, su redundancia con respecto a la tradición romántica y su limitación a las referencias procedentes de la vida cotidiana y contemporánea». Lo que pretendieron Carnero y sus compañeros fue «un replanteamiento y no una huida del intimismo», que se llevó a cabo a través del culturalismo (2004: 23). Las diferencias de esta visión con la mantenida por los tres autores aquí estudiados están claras. Si bien Carvajal, d'Ors y Sánchez Rosillo podrían unirse a Carnero en el rechazo de una poesía concebida exclusivamente «como mensaje», es dudoso que compartieran con él la misma visión de lo que son «significados no problemáticos» y «escasa desviación de la lengua estándar». En primer lugar, porque resulta difícil delimitar unívocamente el carácter «problemático» de los significados de un poema, o su «desviación de la lengua estándar». Pero, aunque esto fuera posible, no parece que la obra de ninguno de ellos tenga estos dos rasgos como notas características. Como corroboran las citas textuales a lo largo de este trabajo, los tres autores estudiados dan más importancia a la eficacia expresiva de sus composiciones que a la búsqueda de lo problemático o lo desusado. Lo que sí está claro es que ninguno de ellos 
tendría problema en redundar «respecto a la tradición romántica», y que ni mucho menos consideraría «las referencias procedentes de la vida cotidiana y contemporánea» como una «limitación». Ya se ha expuesto suficientemente cómo todos ellos afirman explícitamente el carácter autobiográfico de su poesía, no rehúyen el tono intimista o sentimental, y utilizan sus experiencias personales como materia prima de su obra.

La visión que tienen estos tres autores del panorama poético de la posguerra también difiere de la de Carnero. Antonio Carvajal ha declarado su admiración por algunos de los poetas de ese período: «Soy un hijo de mi tiempo y nací a la poesía leyendo lo que en mi tiempo se debía leer y los modelos que me señalaban los poetas que consideré modélicos: Otero [...], Hierro [...], Celaya [...]» (Torés García, 2002: 513). También considera que, cuando empezó a leerlos, todos ellos ya se habían convertido en clásicos, junto a los autores vivos de la generación del 27 (García, 1999: 32). De hecho, el poeta granadino jamás ha considerado que estos escritores fueran un modelo que debía rechazarse. En lugar de eso, los considera «todo el germen de la renovación poética española que ahora son figuras cimeras como, por ejemplo, José Hierro» (Guatelli-Tedeschi, 2004: 94), y el «ejemplo supremo» de Blas de Otero, injustamente ignorado (2004: 213). Por su parte, el desacuerdo de Miguel d'Ors con Carnero no atañe solo a la consideración merecida por los poetas de posguerra, sino también al alcance que pudiera tener esa concepción de la poesía como mensaje. Así lo expresa el autor gallego en la antología Las voces y los ecos:

Es cierto que la sentencia «Poesía es comunicación», dictada por Vicente Aleixandre hacia 1947, fue tomada como consigna por innumerables líricos (que, en general, la interpretaron como «Poesía es lo comunicado»), pero lo fue mucho más en el nivel de la teoría (es decir, en el del «deber ser») que en el de la práctica de la creación poética. [...] Resulta dificilísimo encontrar en ese período piezas que lleven el tan proclamado «contenutismo» humanístico, social o político hasta el extremo de servirse de un lenguaje absolutamente discursivo o coloquial, como si todo el valor del poema residiera en su «mensaje». Nadie, por mucho que ansiara «transformar el mundo» con su poesía, llegó a prescindir de una lengua específicamente poética. Y estoy refiriéndome a los autores integrados en la corriente dominante, porque si atendemos a los que estaban al margen de ella, como Juan Ruiz Peña, Aurelio Valls, los del grupo Cántico, Alfonso Canales, Juan Eduardo Cirlot, Carlos Edmundo de Ory, Rafael Guillén, Manuel Alcántara, Carlos Murciano, etc., las cosas son todavía más claras (García Martín, 1980: 130).

Finalmente, Eloy Sánchez Rosillo ha expresado su distancia respecto al «replanteamiento» del intimismo que, según Carnero, llevaron a cabo él y sus compañeros novísimos. No parece que Sánchez Rosillo, al comienzo de su carrera literaria, estuviera muy deslumbrado por el culturalismo y los mecanismos distanciadores de la nómina castelletiana, porque, al componer sus prime- 
ros libros, lo hizo sin tener en cuenta cómo escribían «los poetas españoles de mi edad, que no eran otros que los llamados novísimos, de los que no sabía demasiado en ese tiempo y que a mi modo de ver escribían como en broma» (2005: 23). En realidad, sí podría hablarse de cierta continuidad entre la forma de concebir la poesía que tienen Carvajal, d'Ors y Sánchez Rosillo y la de los primeros poetas de la posguerra, no tanto en lo que esta tuvo de rehumanización y compromiso social, sino en lo que respecta a la confianza en el lenguaje como instrumento de comunicación y aprehensión de la realidad — aun reconociendo sus limitaciones - y de modificación — aunque sea de manera indirecta — de esta última.

\section{Bibliografía Citada}

Barella, Julia (1981). «Poesía en la década de los 70: En torno a los "Novísimos"», Ínsula. 410 , pp. 8-10.

Barella, Julia (1983). «La reacción veneciana: poesía española en la década de los setenta», Estudios Humanísticos. 5, pp. 69-76.

Barella, Julia (1988). «Sobre la poesía de los 70», Ínsula. 498, p. 8-10.

Barroso, Elena (1991). Poesía andaluza de hoy (1950-1990). Sevilla: Biblioteca de Cultura Andaluza.

Carnero, Guillermo (1983). «La corte de los poetas», Revista de Occidente. 23, pp. 45-48.

Carnero, Guillermo (2004). Poética y poesía. Madrid: Fundación Juan March.

Carvajal, Antonio (1983). Extravagante jerarquía: poesía 1968-1981. Madrid: Hiperión.

Carvajal, Antonio (1994). Ciudades de provincia. Jaén: Diputación Provincial de Jaén.

Carvajal, Antonio (1995). De métrica expresiva frente a métrica mecánica: ensayo de aplicación de las teorías de Miguel Agustín Príncipe. Granada: Universidad de Granada.

Carvajal, Antonio (2002). «Una reflexión sobre la poesía», Extramuros. 25, pp. 18-19.

Carvajal, Antonio (2004a). Los pasos evocados. Madrid: Hiperión.

Carvajal, Antonio (2004b). Poética y poesía. Madrid: Fundación Juan March.

Chicharro, Antonio (2000). «De la espacialidad poética de la Colina Roja. Aproximación a La presencia lejana, de Antonio Carvajal», Cuadernos de la Alhambra. 36, pp. 62-73.

García, Manuel (1999). «Entrevista a Antonio Carvajal», Los papeles mojados de Rioseco. 1, pp. 32-38.

García Martín, José Luis (1980). Las voces y los ecos. Gijón: Júcar.

García Martín, José Luis (1992). La poesía figurativa. Crónica parcial de quince años de poesía española. Sevilla: Renacimiento.

García Martín, José Luis (1996). Treinta años de poesía española: 1965-1995. Sevilla/ Granada: Renacimiento/La Veleta.

Guatelli-Tedeschi, Joëlle (2004). La poesía de Antonio Carvajal: consonante respuesta. Madrid: Biblioteca Nueva.

Iravedra, Araceli (2007). Poesía de la experiencia. Madrid: Visor.

Jiménez, José Olivio (1985). «Reafirmación, proximidad, continuidad: notas hacia la poesía española última (1975-1985)», Las nuevas letras. 3-4, pp. 40-47.

Langbaum, Robert (1996). La poesía de la experiencia. El monólogo dramático en la tradición literaria moderna. Julián Jiménez Heffernan (trad.). Granada: Comares. 1. a ed. 1957. 
Lanz, Juan José (1991). «La poesía española: ¿hacia un nuevo romanticismo?», El Urogallo. 60 , pp. 36-45.

Lanz, Juan José (1994). «Primera etapa de una generación. Notas para la definición de un espacio poético: 1977-1982», Ínsula. 565, pp. 3-6.

Lanz, Juan José (2011). Nuevos y novísimos poetas en la estela del 68. Sevilla: Renacimiento.

Luna Borge, José (1991). La generación poética del 70. Sevilla: Qüasyeditorial.

Luna Borge, José (1999). Bazar de lecturas. Sevilla: Renacimiento.

Martín Pardo, Enrique (1990). Nueva poesía española (1970) y Antología consolidada (1990). Madrid: Hiperión.

Mateo Gambarte, Eduardo (2012). «Generaciones literarias», en Eduardo A. Salas (ed.), Ocho calas en el pensamiento literario español contemporáneo. Sevilla: Alfar, pp. 127-161.

Muñoz, Jacobo (1962). «Poesía y pensamiento poético en Luis Cernuda», La caña gris. 6-7-8, pp. 154-166.

Ors, Miguel d' (1972). Del amor, del olvido. Madrid: Rialp.

Ors, Miguel d' (1991). La música extremada. Sevilla: Renacimiento.

Ors, Miguel d' (1992). Punto y aparte. Granada: Comares.

Ors, Miguel d' (1994). La imagen de su cara. Granada: Comares.

Ors, Miguel d' (1999). Hacia otra luz más pura. Sevilla: Renacimiento.

Ors, Miguel d' (2001). 2001: poesías escogidas. Sevilla: Cuadernos de Poesía Númenor.

Ors, Miguel d' (2005). Sol de noviembre. Sevilla: Cuadernos de Poesía.

Ors, Miguel d' (2008). Virutas de taller: 1995-2004. Valencina: Los Papeles del Sitio.

Ors, Miguel d' (2010). Sociedad limitada. Sevilla: Renacimiento.

Pérez Parejo, Ramón (2002). Metapoesía y crítica del lenguaje (De la generación de los 50 a los novísimos). Cáceres: Universidad de Extremadura.

Prieto de Paula, Ángel Luis (1991). La lira de Arión. De poesía y poetas españoles del siglo XX. Alicante: Universidad de Alicante.

Prieto de Paula, Ángel Luis (1996). Musa del 68. Claves de una generación poética. Madrid: Hiperión.

Provencio, Pedro (1993a). «La generación del 70», Cuadernos Hispanoamericanos. 522, pp. $87-102$

Provencio, Pedro (1993b). Poésie espagnole. Les nouvelles générations. Lyon: Presses Universitaires de Lyon.

Sánchez Rosillo, Eloy (1995). Las cosas como fueron. Granada: Comares.

Sánchez Rosillo, Eloy (1996). La vida. Barcelona: Tusquets.

Sánchez Rosillo, Eloy (2005). Poética y poesía. Madrid: Fundación Juan March.

Sánchez Rosillo, Eloy (2008). Oír la luz. Barcelona: Tusquets.

Torés García, Alberto (2002). «Encuentro con Antonio Carvajal», Canente. Revista literaria. 3-4, pp. 511-517.

Utrera Torremocha, María Victoria (2005). «Luis Cernuda en la poesía española del siglo XX», en Salvador Montesa Peydró (coord.), A zaga de tu huella. Homenaje al profesor Cristóbal Cuevas. Málaga: Universidad de Málaga, vol. II, pp. 137-147.

Valente, José Ángel (1962). «Luis Cernuda y la poesía de la meditación», La caña gris. 6-7-8, pp. 29-38.

Fecha de recepción: 29 de abril de 2015.

Fecha de aceptación: 1 de septiembre de 2015. 